\title{
Pedagogy for Basic Design Studio in Learning Architecture: A Qualitative Exploration
}

\author{
Pashmeena Vikramjit Ghom* Dr. Abraham George \\ Department of Architecture and Planning, Indian Institute of Technology, Kharagpur, India
}

\begin{abstract}
Skill in conception and transforming a concept to design is vital for any architect being churned out through the formal education system existing in post-independent India. Basic Design Studio aims to provide the learners with a sound background in design principles and skills by treating design as a basic creative activity leading to higher levels of learning and design. It focuses on improving creativity through practicing established methods, procedure and exercises in creativity, while drawing inspiration from other creative arts, literature, and folk architecture. Further, it facilitates and establishes analogies in other parallel movements in art, literature, cognitive sciences, social sciences, educational psychology, philosophy and architecture all over the globe. This qualitative study addresses the design studio learning experiences of faculty and students alike. It also describes the revelation that design students gain out of their personal learning experiences that illuminate and brighten the outcome of these learning exercises.
\end{abstract}

Keywords: Basic Design, Creativity, learning experiences, pedagogy, philosophy

DOI: $10.7176 / \mathrm{JEP} / 11-3-18$

Publication date: January $31^{\text {st }} 2020$

\section{Introduction}

The design studio is where a learner learns to design creatively and designing is considered the most vital activity for architects. Basic Design Studio is the most important course in the B. Arch curriculum facilitating the young learners to move to spatial thinking, from numerical, and bare rational. It is an essential activity offering the transformational ability for the future architects to become creative designers. Students in Basic Design Studio primarily are taught three aspects of design education; a new spatial language, a number of new skills such as communication, visualization, and representation leading to architectural design thought process. Design expression is also dependent on the medium of graphical and visual communication. The design traditions use all modes of visual media to represent ideas, thoughts, actions, and moods. Sketches, drawing, paintings and threedimensional sculptures and models are used extensively in the transformational process. The first year is a period of transition for students. Most of their classroom experiences are conducted in traditional settings, through lecture and seminars. In design studios, students learn by developing projects under the guidance of a design professor. Through "learning by doing" system, students are expected to develop their creative potential. It, therefore, is of no doubt that the pedagogical approach of the Basic Design Studio gives, the best opportunity for intervening in the learning of architecture and design. In a way, Basic Design Studio offers the opportunity to learn all aspects of architectural expressions, including its aesthetics and practical skills such as drawing, model making, exposure to different materials, real feel of working with materials, time management and presentation skills. It is therefore of great importance to know whether learning effectiveness can be maximized by creative modes in its pedagogy.

\section{History of Basic Design Studio}

18th century industrial revolution is a reason for a renewed method and outlook in designing based on standardization, mechanization requirements and mass production systems emerged. These objects and designs had to be based on and produced without the limitation of the Knowledge per se and ability of technicians and experts since machines interfered in production. Further, the potentials of computerization of design activity is sought after which is conquering the creative ability and need for digital creativity, for a market-driven global architecture prefers efficiency and performance over classical principles of design. In 1847, Henry Cole (Boucharenc, 2006) founded the association of Art Manufactures and advocated the transformation of machine products into aesthetic forms. Instead of commercial determination of industrial revolution in art and design. It was the beginning to spread reflections from England. Industrialization was not advocated to eliminate the difference between art-craft and reformation of production based on hand work. In this way, an art movement was emerged named as 'Arts and Crafts'. William Morris (Yurtsevera, 2012) leads the movement which advocates the understanding of a design produced by hand instead of cheap and poor-quality mass production. Morris wanted to reform the art education, to have new art education for the new requirements, and to make it part of everyday life. The first school on formal design education with the name of 'Bauhaus' was founded under the presidency of Walter Gropius in Germany in 1919. This approach of Gropius' Bauhaus, it was aimed to create a unity of handcrafts which is able to combine pictures, sculpture, and architecture. It was purposed to raise designers and craftsmen who are able to create beautiful and helpful objects convenient to new life system through developing a 
program based on handcrafts. Bauhaus combined both the design education and elements of fine arts by which a school, a program was formed, students were able to contribute to building design and various internal hardware through gathering visual arts and technique. It is the school that provided the opportunity to perform courageous experiments and use imagination through considering the purpose of design.

\section{Basic Design in Pune University}

In India, for Architectural Education the apex body is Council of Architecture. Council of Architecture has prescribed the guidelines for the formulation of the Architectural Curriculum and Syllabus. Basic design is taught in the first year as per Council of Architecture. However, in Pune University, according to the 2008 pattern, Basic Design is offered in the first two years. First-year deals with visual grammar, element, and principles of design, 2D and 3D composition, Anthropometry, Design of an object in everyday use, Study of building by application of aesthetic appraisal. The second year is expected to enhance creativity through Creation, Creativity, and Motivation, Psychological qualities, Skills for expressions in creativity, Experience and memory in design, Fantasy, imagination, and reality in design, Mental Blocks to creativity: Mental and physical techniques for improving creativity, searching for inspiration for enhancing creativity. The main objective of the research is to describe the exercises taken in the classrooms of a first year and second year of architecture with learning outcome which will help the students to develop their own acceptable product.

\subsection{The Pedagogical approach}

Although pedagogy deals with the science of teaching, as far as basic Design is concerned, it should be more provocative and potentially liberating forms of human exchange. It should focus on what is important to know, how it is to be known, and how this knowledge produced helps to construct social identities or production. Basic Design Studio is the way to develop creative design processes which always has its own value in architectural education. In reality, none of the architectural built and unbuilt structure that appear spontaneously as complete entities. Process fulfils an important role within architecture and the design process that is beneficial for the architect's own development. There are few master architects, who place major of importance upon their creative process. They argue that buildings don't create meaning on their own but on their connections with external factors i.e. site mapping with emphasis on tangible links to the landscape or human context surrounding the site. (Libeskind, 1999) Daniel Libeskind about his Jewish Museum explains "I felt that the physical trace of Berlin was not the only trace, but rather that there was an invisible matrix or anamnesis of connections in a relationship. I found this connection between figures of Germans and Jews. I felt that certain people and particularly certain writers, composers, artists, and poets formed the link between Jewish tradition and German culture. So, I found this connection and I plotted an irrational matrix which was in the form of a system of intertwining triangles which would yield some reference to the emblematic of a compressed and distorted star: the yellow star that was so frequently worn on this very site." This is an interesting conceptual connection which creates an experience impactful that measures the success of the building, the ability of the building to shape its visitors' experiences in a particular way is the way we should judge designs to be great or abysmal. That's why "Process" is valuable to understand because of how it explains the spatial experiences are manipulated.

Tell me and I forget. Teach me and I remember. Involve me and I learn. (Benjamin Franklin). Basic Design can be enhanced more by the curiosity and experiences of students than by the theoretical content of the subject matter taught. Learning by doing is an effective teaching method for basic design.

Basic Aspect of Basic Design Education

- Learning and practicing a number of new skills, such as visualization and Representation

- Learning a new language of graphics and images.

- Learning to think architecturally and spatially.

- Trying to blend artistic parameter with social parameter in evolving meaning.

- Three Concerns of Architectural Design that can be mitigated through basic design are

- The relation of Architecture and Human being, in their complex settings.

- Architecture as the art of composing spaces dimensionally accurate and built with different materials.

- Architecture as Technology to achieve better quality and performance.

3.1.1 Basic Design studio projects given in Pune University

Project 1: Project on Line, Plane and Volume (Creating a 3D Composition)

Being the first exercise, it is based on experimentation. Base or 2D composition is a painting of artist Mondrian and Malevich. Students have to work in the third dimension, converting a line into planes, shapes into volume. Parameters are set for minimum and maximum heights.

Design Process:

Step 1: Prepare a base of given 2D composition on Paper as drawing.

Step 2: Extrude line or shape into plane and volume Students are free to explore in their own intuitive ways so as to creative outcomes as creative three-dimensional forms. 
Step 3: In the three-dimensional form add cut-outs for visual connectedness and better flow of spaces. This given then an idea that transcends to their design of massing at higher levels.

\section{Students Outcome:}
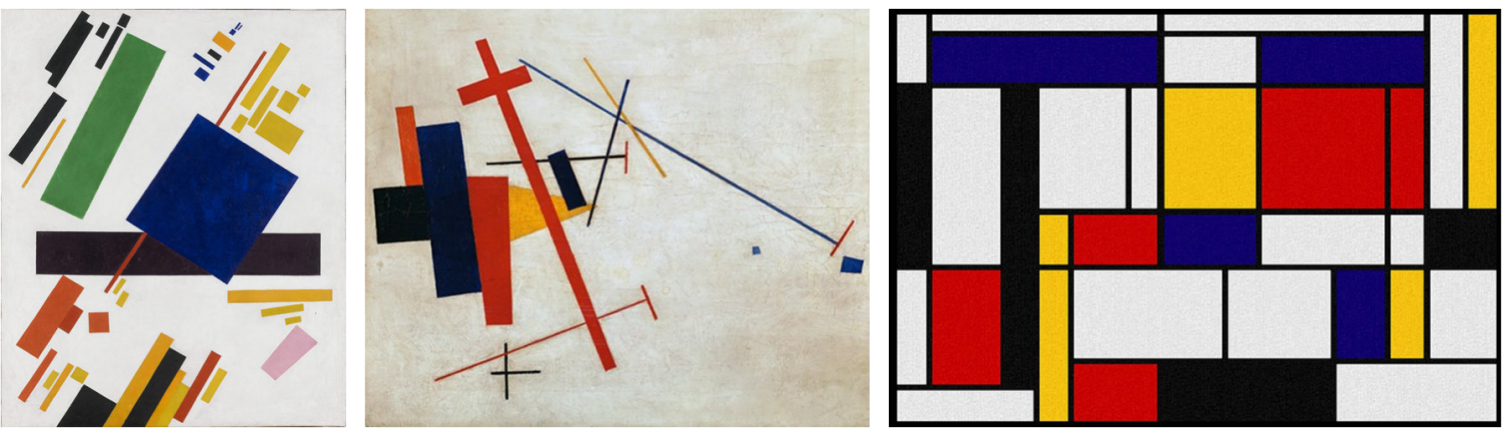

Stage 1: Paintings of Artist Mondrian and Malevich as a base i. e. 2D Composition (Source: Author)

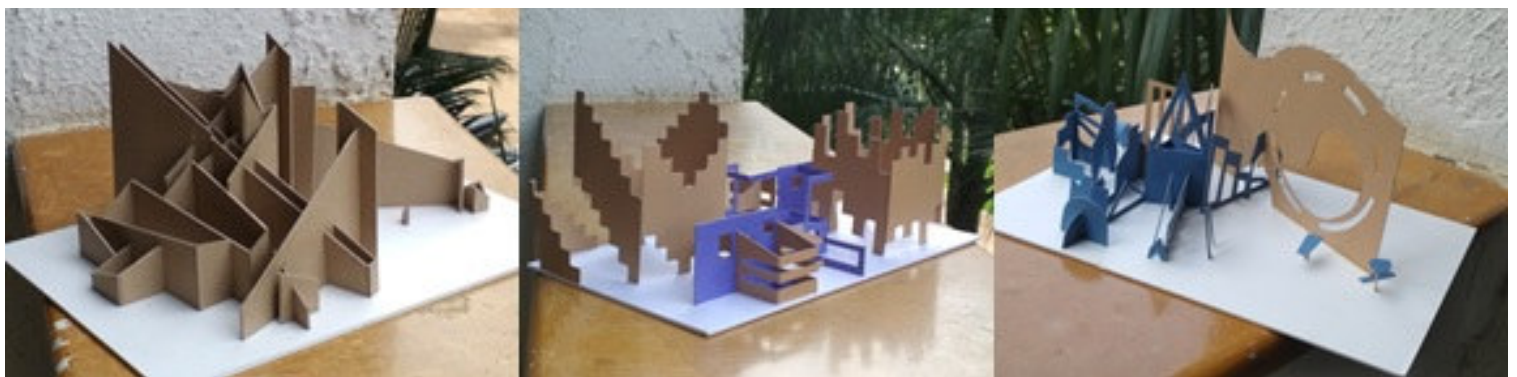

Stage 2 and 3: Students output of 3D composition with extrusion and cut outs. (Source: Author)

Such an attempt enhances the potential of Basic Design as a process to transform the learner's ability in terms of space and dimensions, explorations of colors and textures, light and shade. Therefore, basic design purpose here as vital 'tool' of transformation of learners to architects.

\section{Project 2: Garden Shelter from Paper Sculpture}

Design Process:

Step 1: A simple thin sheet of paper can be folded and converted into a solid form with cut-outs and color application.

Step 2: Above form to be reconstructed with thicker material. Size and shape can be modified to make an expression of architectural form. The openings can relate to light and ventilation, visual connectedness of path and movement to facilitate performance of space. The best angle of vision conforms to the entrance.

Step 3: Levels are introduced internally and externally to add to the sense of movement as space.

Step 4: Application of color to make visually appealing which will depend mostly on the cultural background and exposition of the learner. Professors act as agent to give guidance and crits not mocking or making fun of students. This way the personal confidence of learner are built up along the course of project.

\section{Students Outcome:}
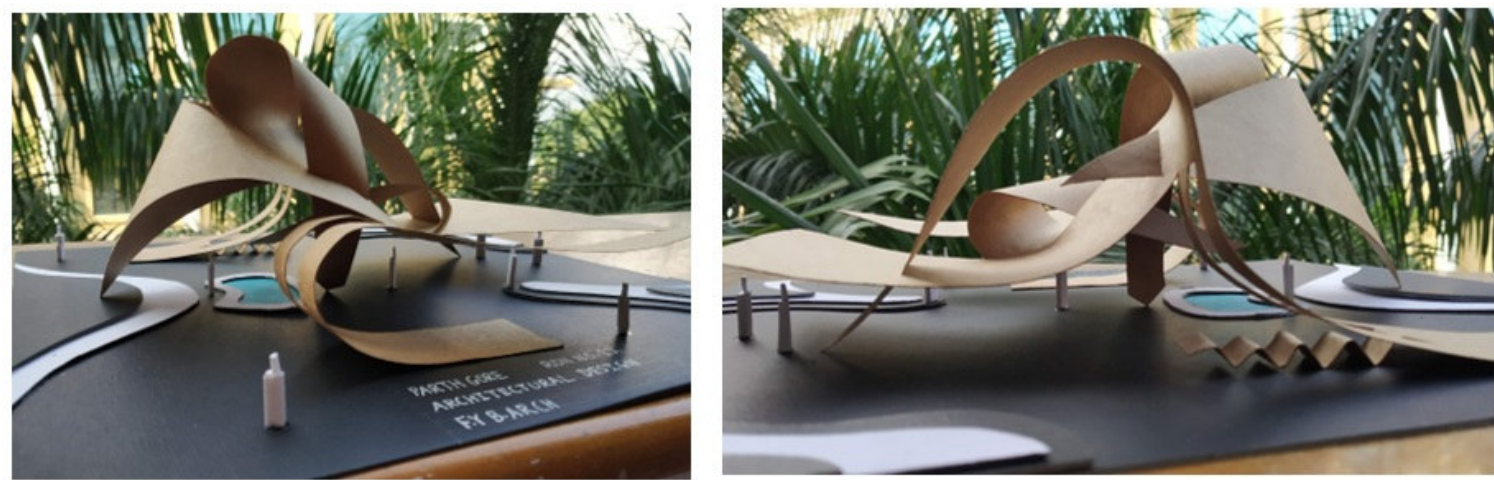

Students output of Garden Shelter (Source: Researcher)

\section{Conclusion}

In the professional course like architecture, there should be a purpose and application of every subject. Visual art and Basic designs are specializations or skills inevitable in developing a sense of aesthetics in design. When the 
theory is applied, there is extensive involvement of the student in applying the theories and techniques into their design through the design process. Students who had little or no exposure to formal and compositional basic concerns produced an unsophisticated design with poor organization of spaces. Since compositional skill is scanty, in spite of any concept behind the design, it hardly produces an efficient, exciting, performing composition of spaces. This may be particularly evident in complex problems where the of the function need to be grouped and sub grouped with hierarchy. Design skill knowledge may be introduced in the early stages, but it should be revisited with more and more complexity and application later on.

\section{References}

Boucharenc, C., 2006. Research on Basic Design Education:An International Survey. International Journal of Technology and Design Education, pp. 1-30.

Cho, Y. J., 2011. Pedagogy of Aesthetics: A Study of Three Architectural Design Studios, s.1.: Doctor of Philosophy, University of Missouri-Columbia.

Farivarsadri, G., 2001. A Critical View on Pedagogical Dimension of Introductory Design in Architectural Education. $A E E$.

Ghom, P. V., 2017. Use of Abstraction in Architectural Design Process (in First Year Design Studio). International Journal of Engineering Research and Technology, Volume 10, pp. 118-122.

Libeskind, D., 1999. Jewish Museum Berlin. Berlin: G \& B Intl; n edition.

Lueth, P. L. O., 2008. The Architectural design studio as a learning environment: a qualitative exploration of architecture design student learning experiences in design studios from first-through fourth-yea. Iowa: Retrospective Theses and Dissertations.

Parashar, S. \& Ghom, P. V., 2018. Natural Analogues as Emerging Nature-Based Parameter for Built. International Journal of Engineering Research, 11-12 January, 7(3), pp. 231-234.

Yurtsevera, B., 2012. Re-thinking bauhaus on the context of architectural education. ELSEVIER. 